\title{
Análise de modelo para projeto e desenvolvimento de serviços: uma pesquisa-ação em uma empresa de transporte rodoviário de passageiros
}

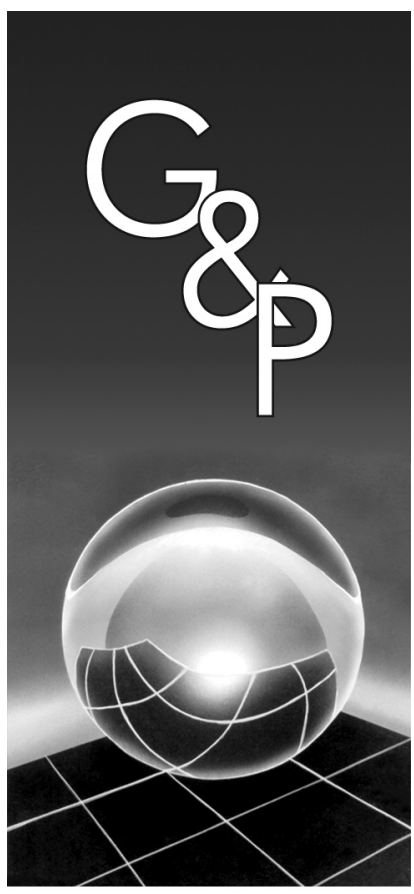

\author{
Vanessa Cristhina Gatto Chimendes \\ Carlos Henrique Pereira Mello \\ Anderson Paulo de Paiva
}

\section{Resumo}

O objetivo deste trabalho é analisar a implantação de um modelo de referência para o projeto e desenvolvimento de serviços em uma empresa de transporte rodoviário de passageiros. O intuito principal é minimizar três problemas relativos ao processo de desenvolvimento de serviços, pela ausência de: uma abordagem sistemática; documentos e registros que assegurem o controle do histórico de criação e melhorias para os serviços; testes documentados para verificação e validação do serviço desenvolvido. O modelo de referência foi escolhido por meio da análise de variância multivariada (Manova) e a pesquisa empregou a estratégia da pesquisaação. $O$ objeto de estudo foi o desenvolvimento de um serviço de bilhetagem eletrônica para uma empresa de transporte rodoviário. A pesquisa proporcionou recomendações para o aperfeiçoamento do modelo de referência e para a implantação de um processo sistemático de desenvolvimento de serviços para a empresa.

Palavras-chave: Processo de desenvolvimento de serviços. Transporte rodoviário de passageiros. Modelos de referência. Análise de variância multivariada (Manova). Serviços.

\section{Introdução}

O Brasil tornou-se, nas últimas décadas, uma economia na qual o setor serviços representa quase dois terços do emprego urbano metropolitano e responde por mais da metade do PIB, numa trajetória semelhante à evolução econômica dos países desenvolvidos. (MELO et al., 1998).

A dificuldade encontrada no tratamento das dimensões para o projeto, planejamento, gestão e controle das operações de serviços mostra que um tópico, em especial, vem ganhando cada vez mais projeção na literatura: o projeto e desenvolvimento de serviços. Com a crescente expansão do setor de serviços, administradores que não estiverem atentos para a utilização de uma linguagem sistemática do processo ficarão inevitavelmente à margem de obter vantagens competitivas satisfatórias. Essas sistemáticas estruturadas poderão impulsionar o desenvolvimento de serviços (MELLO; CHIMENDES; TURRIONI, 2005).

De acordo com Shostack (1984), as falhas em serviços decorrem da falta de um método sistemático para projeto e controle dos serviços. Partindo-se dessa afirmação, podem-se destacar três problemas relativos ao processo de desenvolvimento de serviços, pela ausência de: uma abordagem sistemática; documentos e registros que assegurem o controle do histórico de criação e melhorias para os serviços; testes documentados para verificação e validação do serviço desenvolvido.

Buscando contribuir com o campo do conhecimento, o objetivo principal deste trabalho é analisar a implantação de um modelo para projeto e desenvolvimento de serviços em uma empresa de transporte rodoviário de passageiros, com o intuito principal de minimizar os três problemas citados. Espera-se que as observações obtidas durante a pesquisa de campo possibilitem: a construção de um processo sistemático e documentado para o desenvolvimento de serviços na empresa objeto de estudo; e a elaboração de recomendações para a melhoria do modelo estudado.

Para atingir esses objetivos, a pesquisa empregou o método da pesquisa-ação para uma análise qualitativa da implantação do modelo de referência adotado na empresa objeto de estudo. Bryman (1989) considera que a pesquisa-ação é uma abordagem da pesquisa social 
aplicada na qual o pesquisador e o cliente colaboram no desenvolvimento de um diagnóstico e para a solução de um problema, por meio dos quais as descobertas resultantes irão contribuir para a base de conhecimento em um domínio empírico particular.

O procedimento da pesquisa adotou os passos propostos por Coughlan e Coghlan (2002): entender o contexto (identificação do problema) e definir a proposta da pesquisa; coletar, realimentar e analisar dados; planejar, implementar e avaliar as ações; monitoramento (ou seminário), realizado a cada ciclo da pesquisa-ação, de forma que o planejamento, a implementação e a avaliação acontecem de modo contínuo ao longo do tempo.

O problema identificado na unidade de análise foi a ausência de um modelo de referência para o desenvolvimento de serviços. Para buscar resolver esse problema, procedeu-se a uma revisão de literatura a respeito de modelos de referência para serviços, que é apresentada no item 2 do presente trabalho. A seleção do modelo de referência adotado para a presente pesquisa foi feita pela elaboração de um questionário com questões fechadas respondidas por informantes-chave da unidade de análise. Os dados foram analisados por análise de variância multivariada e permitiram a seleção de um modelo de referência.

O item 3 apresenta uma síntese das principais fases e etapas do modelo de referência selecionado e o item 4 descreve as principais características da unidade de análise e a pesquisa empírica realizada pela pesquisaação. O item 5 apresenta as conclusões e recomendações finais do presente trabalho. A presente pesquisa foi realizada entre os meses de março de 2005 e dezembro de 2006.

\section{Análise comparativa dos modelos para projeto e desenvolvimento de serviços}

Mello (2005) afirma que a forma como as organizações buscam desenvolver novos produtos varia desde empresas que querem ser pioneiras em um determinado mercado até aquelas que só o fazem quando pressionadas. Sendo assim, o processo de desenvolvimento de serviços deve ser estruturado de maneira a garantir que cada etapa seja cumprida de forma satisfatória.

Os modelos estabelecem um modo de pensar, desempenham um papel de referência, operando como prescrição para os agentes que tomam a decisão a respeito de práticas a serem empregadas nas operações e processos (LIMA, 2001). Amaral (2002) define o modelo de referência como um modelo de aplicação mais amplo e geral, que pode ser utilizado como referência para o desenvolvimento de modelos específicos e/ou situações específicas. Os modelos de referência podem ser aplicados tanto para novos serviços quanto para melhorias em serviços existentes.

Fitzsimmons e Fitzsimmons (2000) desenvolveram um estudo em que classificaram os modelos de referência para o desenvolvimento de serviço em três categorias:

a) modelos parciais: consistem somente de elementos que completam o processo ou relacionados com etapas específicas do processo de desenvolvimento de novos serviços;

b) modelos convergentes: baseados ou originados das etapas do modelo de desenvolvimento de produtos proposto pela consultoria de Booz, Allen e Hamilton em 1982; e

c) modelos completos: apresentam uma visão holística do processo de desenvolvimento de serviços.

A presente pesquisa empreendeu uma revisão de literatura com o objetivo de realizar uma análise comparativa de alguns modelos de referência para o projeto e desenvolvimento de serviços citados na literatura, buscando destacar similaridades, diferenças e inter-relações de suas etapas constituintes. Com base nesta análise, pretende-se selecionar um dos modelos, com base em critérios definidos, para realização da verificação de sua adequação em um objeto de estudo. A escolha desses modelos se deu pela sua relevância na literatura pesquisada e também pela possibilidade de acesso do pesquisador a essas publicações. Buscou-se na literatura modelos de referência locais e internacionais aplicados especificamente à área de transportes, porém a pesquisa revelou que esses modelos não tratavam do processo de desenvolvimento de serviços para transportes (BARAT, 1989; GEERLINGS; KLEMENTSCHITZ; MULLEY, 2006). A análise comparativa é apresentada no Quadro 1. A classificação desses modelos em parciais, convergentes ou completos foi baseada no estudo de Fitzsimmons e Fitzsimmons (2000).

O modelo de Cowell (1988), classificado como um modelo parcial, contempla apenas uma parte do processo desenvolvimento de serviço e considera que cada etapa utilizada no desenvolvimento vai depender das características particulares do serviço.

Já o de Scheuing e Johnson (1989), classificado como completo, valoriza a geração de idéias a partir de fontes internas e externas da organização e o treinamento de pessoal. Ele não contempla atividades para melhoria de serviços já existentes, tornando-o assim propício para o desenvolvimento de serviços inovadores.

A proposta de Bowers (1989) pode ser considerada um modelo de convergência e, talvez por ser um modelo simplificado, não destaca a importância das atividades de comercialização e revisão de pós-lançamento.

O modelo de Ramaswamy (1996), que pode ser considerado como parcial, apresenta uma atenção especial com o ciclo de vida do serviço; enquanto o de Tax 
Quadro 1. Análise comparativa dos modelos para projeto e desenvolvimento de serviços.

\begin{tabular}{|c|c|c|c|c|}
\hline Autor e ano & $\begin{array}{l}\text { Características } \\
\text { gerais dos modelos }\end{array}$ & Pontos fortes & Limitações & Observações \\
\hline $\begin{array}{l}\text { Cowell } \\
(1988)\end{array}$ & $\begin{array}{l}\text { Preparação para o desenvol- } \\
\text { vimento e o lançamento de } \\
\text { novos serviços em empresas } \\
\text { que estabelecem uma cultura } \\
\text { para empreendedores que or- } \\
\text { ganizam a criação de idéias. } \\
\text { Modelo composto por sete } \\
\text { fases. }\end{array}$ & $\begin{array}{l}\text { Ordem sistemática } \\
\text { para redução de risco } \\
\text { de produtos/serviços } \\
\text { deficientes. Sequiên- } \\
\text { cia simples e comum, } \\
\text { considerando o grau } \\
\text { de inovação. }\end{array}$ & $\begin{array}{l}\text { Não apresenta uma } \\
\text { fase posterior à fase } \\
\text { de comercialização, } \\
\text { como, por exemplo, } \\
\text { uma fase de avalia- } \\
\text { ção para revisão de } \\
\text { pós-lançamento. Não } \\
\text { contempla uma fase } \\
\text { de análise estratégi- } \\
\text { ca. }\end{array}$ & $\begin{array}{l}\text { Ressalta a importante diferença entre } \\
\text { desenvolvimento de novos produtos e } \\
\text { desenvolvimento de novos serviços con- } \\
\text { siderando os seguintes problemas: deri- } \\
\text { vados das características dos serviços, na } \\
\text { pesquisa dos novos serviços; associados } \\
\text { com características dos novos serviços, } \\
\text { com os modelos do processo de serviços } \\
\text { e com o uso de pessoas nos novos servi- } \\
\text { ços (intangibilidade e inseparabilidade). }\end{array}$ \\
\hline $\begin{array}{l}\text { Scheuing } \\
\text { e Johnson } \\
(1989)\end{array}$ & $\begin{array}{l}\text { É sistemático para desenvol- } \\
\text { vimento de novos serviços, } \\
\text { desenvolvido por meio de } \\
\text { experiências empíricas com } \\
\text { quatro etapas e quinze fa- } \\
\text { ses. É um resultado de uma } \\
\text { pesquisa exploratória no de- } \\
\text { senvolvimento de novos ser- } \\
\text { viços. Para formar uma rede } \\
\text { de trabalho sistemático para } \\
\text { gerenciamento e desenvolvi- } \\
\text { mento de novos serviços. }\end{array}$ & $\begin{array}{l}\text { Estrutura apropria- } \\
\text { damente desenhada e } \\
\text { um processo cuidado- } \\
\text { samenteharmonizado. } \\
\text { Modelo sofisticado, } \\
\text { que oferece detalhes } \\
\text { dos critérios dentro do } \\
\text { complexo e importan- } \\
\text { te processo. }\end{array}$ & $\begin{array}{l}\text { Modelo mais utili- } \\
\text { zado em desenvol- } \\
\text { vimento de serviços } \\
\text { inovadores. Não con- } \\
\text { sidera a sistemática } \\
\text { de revisão de fases } \\
\text { (stage-gates). }\end{array}$ & $\begin{array}{l}\text { O modelo é baseado na extensa parte cen- } \\
\text { tral da literatura, relacionado com o ge- } \\
\text { renciamento de novos produtos, porém a } \\
\text { estrutura do modelo reflete as condições } \\
\text { únicas predominantes nas indústrias de } \\
\text { serviços. Como ponto principal destaca- } \\
\text { se a interação entre o projeto e o teste de } \\
\text { serviço, destacando a importância da ge- } \\
\text { ração de idéias, considerando os aspectos } \\
\text { internos e externos da organização e o } \\
\text { treinamento do pessoal para a entrega do } \\
\text { novo serviço. }\end{array}$ \\
\hline $\begin{array}{l}\text { Bowers } \\
\text { (1989) }\end{array}$ & $\begin{array}{l}\text { Sugere três formas que per- } \\
\text { mite o aperfeiçoamento do } \\
\text { desenvolvimento de um } \\
\text { novo serviço: pela geração } \\
\text { de idéias, da avaliação e de- } \\
\text { senvolvimento do serviço e } \\
\text { do teste de marketing. }\end{array}$ & $\begin{array}{l}\text { Modelo desenvolvido } \\
\text { em indústrias de ser- } \\
\text { viços com caracterís- } \\
\text { ticas inovadoras. }\end{array}$ & $\begin{array}{l}\text { Simplicidade do mo- } \\
\text { delo, não destacando } \\
\text { atividades impor- } \\
\text { tantes, como, por } \\
\text { exemplo, a comer- } \\
\text { cialização e a revisão } \\
\text { pós-lançamento. }\end{array}$ & $\begin{array}{l}\text { Embora não esteja explícito no modelo, } \\
\text { retrata o resultado da pesquisa no pro- } \\
\text { cesso de desenvolvimento de serviço. } \\
\text { Considera a estratégia de negócio e a } \\
\text { análise do negócio como as duas maio- } \\
\text { res atividades responsáveis pelo desen- } \\
\text { volvimento de novos serviços. }\end{array}$ \\
\hline $\begin{array}{l}\text { Ramaswamy } \\
\text { (1996) }\end{array}$ & $\begin{array}{l}\text { Compreende duas etapas } \\
\text { e oito fases e a concepção } \\
\text { completa do ciclo de vida } \\
\text { do serviço, considerando as } \\
\text { suas atividades. }\end{array}$ & $\begin{array}{l}\text { Considera como pon- } \\
\text { to importante as ne- } \\
\text { cessidades dos clien- } \\
\text { tes e os atributos dos } \\
\text { serviços. }\end{array}$ & $\begin{array}{l}\text { O fim de cada ciclo } \\
\text { está condicionado } \\
\text { ao mercado e a seus } \\
\text { competidores. A tec- } \\
\text { nologia e os clientes } \\
\text { estão baseados na } \\
\text { extinção dos proces- } \\
\text { sos já obsoletos e na } \\
\text { necessidade de novos } \\
\text { desenhos. }\end{array}$ & $\begin{array}{l}\text { A concepção do modelo pode ser apli- } \\
\text { cada para qualquer problema no projeto. } \\
\text { Considerando a estrutura do projeto em } \\
\text { relação ao processo de serviços e à ad- } \\
\text { ministração do serviço }\end{array}$ \\
\hline $\begin{array}{l}\text { Tax \& Stuart } \\
\text { (1997) }\end{array}$ & $\begin{array}{l}\text { Considera o impacto que um } \\
\text { novo serviço pode ter sobre } \\
\text { um sistema de serviço já } \\
\text { existente. Modelo complexo } \\
\text { que atenta para a especifica- } \\
\text { ção da tomada de decisão, } \\
\text { definição dos resultados e } \\
\text { dos desafios da implementa- } \\
\text { ção. Processo interativo. }\end{array}$ & $\begin{array}{l}\text { Identificação de fa- } \\
\text { tores associados ao } \\
\text { projeto e à introdução } \\
\text { do serviço. Apresenta } \\
\text { fatores de sucesso e } \\
\text { insucesso no plane- } \\
\text { jamento e projeto de } \\
\text { serviços. }\end{array}$ & $\begin{array}{l}\text { Modelo mais aplica- } \\
\text { do na melhoria de um } \\
\text { serviço já existente. } \\
\text { Não considera a sis- } \\
\text { temática de revisão } \\
\text { de fases. }\end{array}$ & $\begin{array}{l}\text { O modelo destaca a importância do pla- } \\
\text { nejamento do serviço e a definição das } \\
\text { instalações físicas. Considera a excelên- } \\
\text { cia do projeto e o caminho mais efetivo } \\
\text { e eficiente para alcançar altos níveis de } \\
\text { satisfação do cliente. }\end{array}$ \\
\hline $\begin{array}{l}\text { Bitran e } \\
\text { Pedrosa } \\
(1998)\end{array}$ & $\begin{array}{l}\text { Estruturado sob a ótica das } \\
\text { operações de serviços, sendo } \\
\text { um grupo de atividades com } \\
\text { o objetivo de desenvolver } \\
\text { novos serviços. As opera- } \\
\text { ções observam uma seqüên- } \\
\text { cia temporal. }\end{array}$ & $\begin{array}{l}\text { Mostra a utilização de } \\
\text { ferramentas, métodos } \\
\text { e modelos, aprimoran- } \\
\text { do o conceito de cada } \\
\text { componente do produto } \\
\text { e/ou serviço projetado. }\end{array}$ & $\begin{array}{l}\text { Utilização de uma } \\
\text { única etapa, conside- } \\
\text { rando todas as fases } \\
\text { dentro desta etapa, } \\
\text { dificultando o deta- } \\
\text { lhamento das ativi- } \\
\text { dades. }\end{array}$ & $\begin{array}{l}\text { Considera que o desenvolvimento de } \\
\text { um novo produto e/ou serviço inicia } \\
\text { com um tipo pobre de informação e vai } \\
\text { evoluindo conforme os estágios do de- } \\
\text { senvolvimento, sistematizando o conhe- } \\
\text { cimento. }\end{array}$ \\
\hline
\end{tabular}


Quadro 1. Continuação.

\begin{tabular}{|c|c|c|c|c|}
\hline Autor e ano & $\begin{array}{c}\text { Características } \\
\text { gerais dos modelos }\end{array}$ & Pontos fortes & Limitações & Observações \\
\hline Mello (2005) & $\begin{array}{l}\text { Contempla as principais } \\
\text { lacunas do desenvolvimento } \\
\text { de serviços, inclusive o de } \\
\text { mapeamento do processo de } \\
\text { serviço. Sendo um modelo } \\
\text { objetivo, preciso e baseado } \\
\text { em uma pesquisa científica. }\end{array}$ & $\begin{array}{l}\text { Modelo simples, porém } \\
\text { completo. Inclui etapas } \\
\text { críticas para o projeto de } \\
\text { serviços em empresas } \\
\text { de qualquer porte. } \\
\text { Considera a autonomia } \\
\text { dos funcionários no } \\
\text { processo e apresenta } \\
\text { uma fase de lançamento } \\
\text { de serviço. }\end{array}$ & $\begin{array}{l}\text { Falta sistemática para } \\
\text { definir as especificações } \\
\text { dentro da concepção do } \\
\text { serviço. Não contempla } \\
\text { uma atividade de auto- } \\
\text { rização para início do } \\
\text { projeto. Não considera } \\
\text { a sistemática de revisão } \\
\text { de fases. }\end{array}$ & $\begin{array}{l}\text { Considera as principais } \\
\text { etapas, fases e atividades } \\
\text { para o projeto e desenvolvi- } \\
\text { mento de serviços. Pode ser } \\
\text { classificado como um mo- } \\
\text { delo completo, pois procura } \\
\text { representar o processo de } \\
\text { desenvolvimento de serviço } \\
\text { holisticamente. }\end{array}$ \\
\hline
\end{tabular}

e Stuart (1997), que pode ser considerado como um modelo completo, compreende um ciclo de planejamento que aborda um modelo tradicional de projeto, incluindo as considerações específicas geradas no desenvolvimento de serviço. Como um ponto fraco, pode-se destacar que esse modelo não considera a formulação de objetivos e estratégias, uma vez que foi desenvolvido para melhoria de serviços já existentes.

Bitran e Pedrosa (1998) apresentam um modelo que poderia ser classificado como parcial, desenhado em uma única etapa, o que dificulta o detalhamento das atividades, mas considera o entendimento dos componentes que integram o projeto e como estes componentes se interagem.

Dadas as características propostas por Fitzsimmons e Fitzsimmons (2000), poder-se-ia classificar o modelo de Mello (2005) como completo, pelo caráter holístico que o conjunto de cada uma das suas etapas representa.

Para o levantamento das principais fases de um modelo de referência considerado ideal, utilizaram-se a análise dos pontos fortes e as limitações de cada um dos modelos considerados completos dados pelo Quadro 1, segundo a classificação do Fitzsimmons e Fitzsimmons (2000). Os modelos classificados como parciais e convergentes também colaboraram com a análise, uma vez que uma fase importante poderia não estar presente em um dos modelos considerados como completos. As principais fases consideradas estão descritas no Quadro 2.

Para se tecer uma lógica comparativa entre os modelos estudados, uma análise quantitativa foi proposta a partir de um questionário de pesquisa (Anexo A) para seleção de um modelo para projeto e desenvolvimento de serviços. A principal questão de interesse posta em análise foi: quais dos modelos apresentados podem ser considerados como modelos completos no que tange o atendimento das necessidades de desenvolvimento de serviços na organização? Os critérios adotados na pesquisa tiveram como base o Quadro 2.

Os respondentes selecionados foram escolhidos entre aqueles que faziam parte da equipe de trabalho que iria desenvolver um novo serviço na empresa objeto de estudo. Cada respondente manifestou seu grau de concordância
Quadro 2. Principais fases de um modelo de referência considerado completo.

1) Avaliação estratégica (análise do mercado e dos objetivos corporativos)

2) Geração e seleção de idéias para novos serviços (fontes internas e externas)

3) Definição de especificações para o serviço

4) Definição do pacote e do conceito do serviço

5) Teste do conceito

6) Autorização para o início do projeto

7) Projeto do processo (mapeamento das atividades, controle dos processos, padronização das atividades críticas e recrutamento e treinamento de funcionários de linha de frente e retaguarda)

8) Projeto das instalações do serviço (projeto da parcela tangível do serviço, tais como localização, evidências físicas e espaço físico)

9) Avaliação da capacidade produtiva e da capacidade interna de adaptação às mudanças do novo serviço

10) Teste do serviço (com operação ou lote piloto)

11) Projeto do programa do marketing (implantação e teste)

12) Avaliação de melhoria no processo de projeto do serviço e recuperação de falhas

13) Lançamento do serviço no mercado

14) Revisão pós-lançamento e realimentação

com cada uma das questões da pesquisa, discriminando sua opinião entre as opções de "discordo totalmente"; "discordo com restrições"; "concordo com restrições"; e "concordo totalmente". Para uma posterior análise estatística dos resultados, uma escala numérica, de natureza discreta, foi associada aos níveis concordância, com valores entre 1 (discordo totalmente) e 4 (concordo totalmente).

O pesquisador explicou as etapas e fases de cada um dos modelos estudados para os respondentes escolhidos, sem mencionar seus autores. Os modelos foram identificados por letras, tal que: A - Bowers (1989); B - Bitran e Pedrosa (1998); C - Cowell (1988); D - Tax e Stuart (1997); E - Ramaswamy (1996); F - Scheuing e Johnson (1989); G - Mello (2005). Os questionários foram aplicados a cada respondente individualmente.

Os dados provenientes dos questionários aplicados foram tabulados pelo programa estatístico MINITAB 
versão 14. O conjunto de dados permite realizar uma análise exploratória para identificar o relacionamento entre as variáveis da amostra. Este conjunto de dados pode ser considerado como multivariado, uma vez que existem sete modelos distintos (X), avaliados segundo 19 critérios (Y), estabelecidos de acordo com uma análise prévia, que considerou os pontos fortes e fracos de cada modelo. Na avaliação do modelo mais adequado para o desenvolvimento de serviço, o questionário com os critérios selecionados foi apresentado a um grupo de 11 respondentes (n), participantes de uma equipe de trabalho da empresa considerada como objeto de estudo.

Segundo Rencher (2002), não é conveniente considerar as respostas isoladamente quando elas exibirem estruturas fortes de correlação. Para tratar as 19 questões de maneira conjunta, utilizou-se uma análise de variância multivariada (MANOVA). Se a análise não revelar problemas de correlação, uma ANOVA unidimensional (1 X e $1 \mathrm{Y}$ ) poderia ser aplicada individualmente a cada um dos critérios.

É necessário verificar, neste caso, como as amostras se relacionam, ou seja, o quanto estas são semelhantes segundo as variáveis utilizadas na pesquisa. Com esta finalidade, os dados foram inicialmente submetidos à Manova, na qual cada tratamento (nível de análise ou X) é descrito por um conjunto de múltiplas variáveis dependentes.

Para Pontes (2005), os métodos multivariados da análise de variância, denominados de MANOVA (multivariate analyis of variance), são aqueles em que se procura identificar diferenças significativas entre vetores de médias desses grupos. Estes vetores representam as múltiplas respostas do estudo. A metodologia utilizada para verificar as diferenças entre tratamento na análise multivariada, considerando um delineamento inteiramente casualizado (one-way), pode ser a mesma dos métodos univariados, ou seja, a variabilidade total dos dados é subdividida, de tal forma que se obtém uma parte referente à variação devida às diferenças existentes entre tratamentos e outra referente à variação dentro dos tratamentos. No caso univariado, esta variabilidade é expressa pelas somas de quadrados, enquanto no caso multivariado tem-se uma matriz de soma de quadrados na diagonal principal e de soma de produtos fora dela. A análise multivariada realizada é apresentada na Tabela 1 .
O resultado obtido por meio do teste da análise multivariada identifica que os modelos são diferentes e independentes entre si, porém esta análise não identifica quais modelos são diferentes.

Para se descobrir qual o modelo que mais se distingue dos outros, empregou-se uma Anova com um fator, utilizando-se como resposta o escore de um componente principal do conjunto de critérios. Segundo Rencher (2002), um componente principal é uma combinação linear de um grupo de variáveis que representa sua máxima variação.

A Tabela 2 apresenta o resultado do agrupamento analisado de forma global (PC1).

Os resultados fornecidos pela ANOVA aplicada ao primeiro componente principal $\mathrm{PC} 1$ demonstram que os modelos $\mathrm{A}, \mathrm{B}$ e $\mathrm{C}$ não apresentam diferenças significativas, porém distintas dos modelos $\mathrm{F}$ e G que, por sua vez, também não apresentam diferenças significativas entre si. Assim, a análise revela dois grupos bem distintos (A, B e $\mathrm{C}$ vs. $\mathrm{F}$ e $\mathrm{G}$ ), enquanto que um terceiro grupo (D e E) mantém-se em uma posição intermediária, porém, não diferente dos grupos citados anteriormente.

O teste de correlação apresenta uma correlação negativa entre o escore do primeiro componente principal e as variáveis de resposta originais. Sendo assim, quanto mais negativo o componente principal, maior é a nota que recebe o modelo em um dado critério $\left(\mathrm{Y}_{\mathrm{i}}\right)$.

Analisando a Tabela 2 e a Figura 1, é possível afirmar que, para este conjunto de respondentes, considerando os critérios analisados, o modelo de Mello (2005) é estatisticamente igual ao modelo de Scheuing e Johnson (1989), considerado como completo conforme classificação de Fitzsimmons e Fitzsimmons (2000). A Figura 1 ilustra o gráfico de confiança para o PC1.

Após a aplicação dessas duas análises, resta identificar em quais dos 19 critérios os modelos são equivalentes ou diferentes. Pode-se avaliar também como estes critérios estão correlacionados. Para isso utilizou-se uma análise de variância que permitiu que os vários grupos fossem comparados a um só tempo, neste caso, a variável de interesse deve ter uma distribuição normal e os grupos têm de ser independentes.

A análise de variância avalia se as amostras, que têm variâncias homogêneas, têm médias iguais. A hipótese inicial prevê a igualdade das médias, enquanto que a

Tabela 1. MANOVA.

\begin{tabular}{lccccc}
\hline & Teste & & \multicolumn{2}{c}{ Grau de Liberdade } \\
\hline \multicolumn{1}{c}{ Critérios } & Estatística & Aproximação de F & Numerador & Denominador & Valor de P \\
\hline Wilks' & 0,01976 & 2,629 & 114 & 306 & 0,000 \\
Lawley - Hotelling & 6,59405 & 2,911 & 114 & 302 & 0,000 \\
Pillas's & 2,63949 & 2,356 & 114 & 342 & - \\
Roys & 3,01476 & - & - & - & - \\
\hline
\end{tabular}


Tabela 2. PC1.

\begin{tabular}{cccc}
\hline Modelo & $\begin{array}{c}\text { Número de } \\
\text { respondentes }\end{array}$ & Média & Desvio-padrão \\
\hline A & 11 & 2,185 & 1,697 \\
B & 11 & 1,540 & 2,527 \\
C & 11 & 1,344 & 2,028 \\
D & 11 & $-0,223$ & 2,189 \\
E & 11 & $-0,256$ & 1,787 \\
F & 11 & $-2,269$ & 2,986 \\
G & 11 & $-2,320$ & 1,848 \\
\hline
\end{tabular}

Gráficos de intervalos de confiança de 95\% para PC1

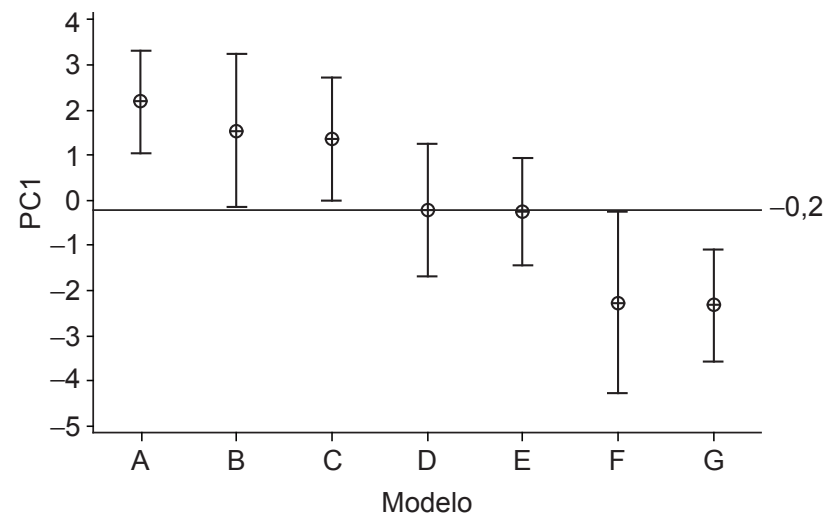

Figura 1. Gráfico de intervalos de confiança para PC1.

hipótese alternativa afirma que pelo menos uma das médias é diferente das demais (o que significa dizer que pelo menos uma amostra não é procedente da mesma população).

O menor nível de significância que pode ser assumido para rejeitar uma hipótese nula é chamado de $p$-value (MONTGOMERY, 2003). Só há significância estatística quando o $p$-value é menor que o nível de significância adotado. Neste trabalho, considerou-se um nível de significância de 5\%. A Tabela 3 apresenta os valores de $p$-value relacionados às questões, o que permitiu avaliar a divergência entre as questões de forma univariada para cada critério. Observa-se, na Tabela 3, que as diferenças significativas estão nas questões que apresentam baixos valores de $p$-value $(\mathrm{P}<0,05)$.

Portanto, as questões que apresentam critérios equivalentes são: Y5, Y9, Y15, Y16, considerando a visão dos 11 respondentes.

O critério proposto por Fitzsimmons e Fitzsimmons (2000) para que um modelo seja considerado completo, ou seja, uma representação holística do processo de desenvolvimento de serviços indica que o modelo de Scheuing e Johnson (1989) atende a esta constatação. Como o modelo proposto por Mello (2005) mostrou-se estatisticamente igual ao modelo de Scheuing e Johnson (1989), pode-se considerar tal modelo como completo e
Tabela 3. Valores de $p$-value relacionados às questões.

\begin{tabular}{cccc}
\hline Questões (Y) & p-value & Questões (Y) & p-value \\
\hline Y1 & 0,002 & Y11 & 0,000 \\
Y2 & 0,000 & Y12 & 0,002 \\
Y3 & 0,000 & Y13 & 0,039 \\
Y4 & 0,016 & Y14 & 0,000 \\
Y5 & 0,365 & Y15 & 0,841 \\
Y6 & 0,001 & Y16 & 0,279 \\
Y7 & 0,035 & Y17 & 0,000 \\
Y8 & 0,000 & Y18 & 0,001 \\
Y9 & 0,363 & Y19 & 0,000 \\
Y10 & 0,011 & - & - \\
\hline
\end{tabular}

referência para o estudo, podendo ser utilizado no projeto de um novo serviço ou na melhoria de um serviço existente.

\section{Síntese das principais etapas do modelo adotado}

Mello (2005) propôs um modelo para o desenvolvimento de serviços a partir de um estudo comparativo dos principais modelos consagrados existentes, analisando as estruturas de modelos para projeto de produtos e para projeto de serviços. O modelo proposto por Mello (2005) é composto por quatro etapas, como mostra a Figura 2.

Mello (2005) afirma que a primeira etapa de concepção do serviço inicia-se com pesquisas sobre as necessidades e expectativas dos clientes e do mercado para a criação ou melhoria de um serviço. Com o auxílio das estratégias competitivas, as idéias são selecionadas e o conceito e o pacote de serviço devem ser definidos. Faz-se ainda um levantamento das especificações para o processo de prestação de serviço a ser projetado.

A segunda etapa do processo identifica a definição dos principais processos e suas respectivas atividades necessárias para a realização, entrega ou manutenção de um serviço. E, pelas especificações levantadas na primeira etapa, faz-se uma integração dos processos e atividades necessárias para a entrega dos serviços, considerando o ambiente, a relação entre funcionários e clientes, produzindo um nível adequado de desempenho.

A terceira etapa do modelo é o projeto das instalações do serviço, que Mello (2005) considera como a parcela tangível do serviço proposto. Nesta etapa, é realizada a definição das instalações físicas (layout) onde o serviço será entregue e de atributos físicos importantes na percepção do cliente a respeito da qualidade do serviço, tais como localização, decoração, etc., bem como a definição da sua capacidade produtiva. 


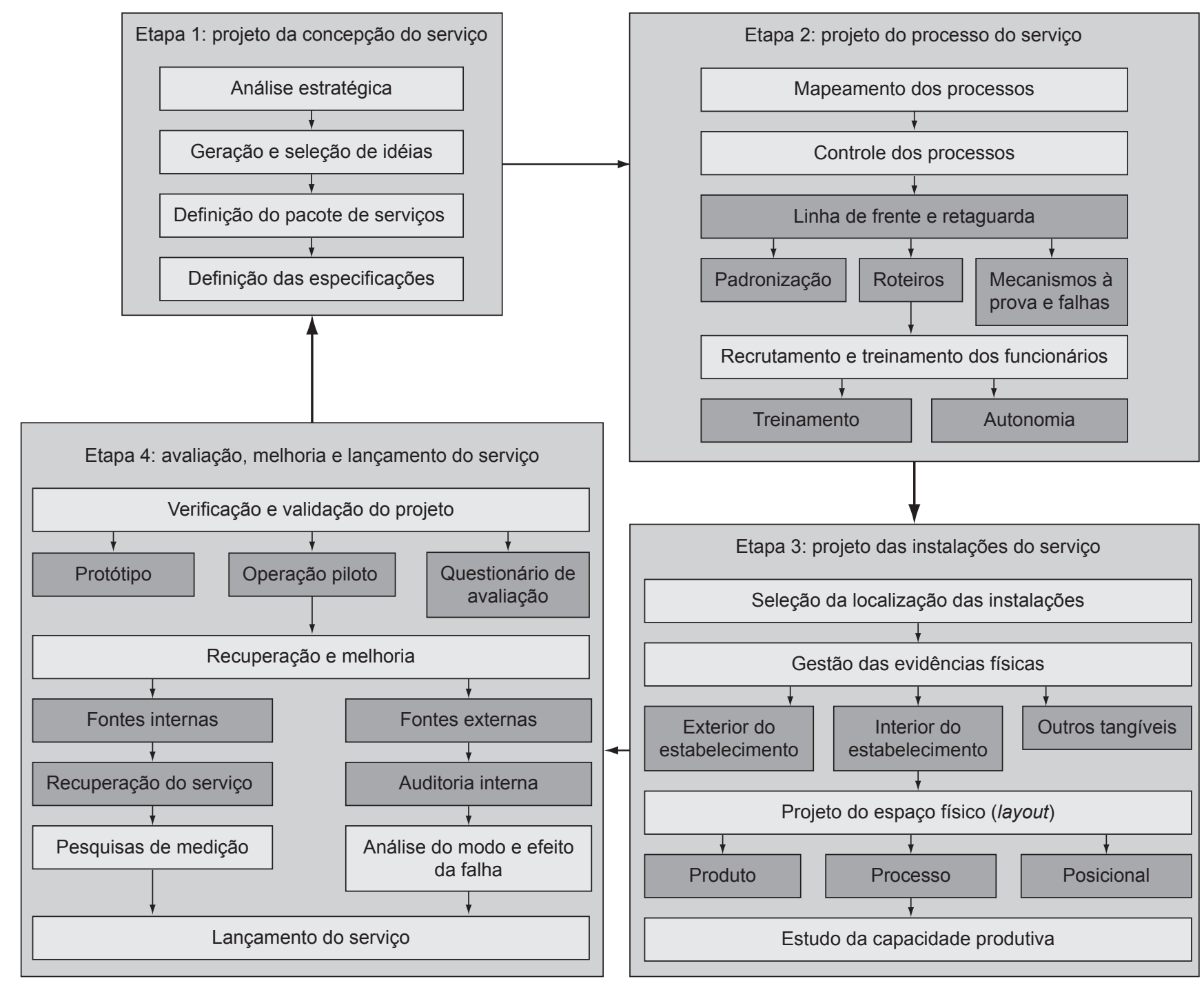

Figura 2. Modelo para projeto e desenvolvimento de serviços (MELLO, 2005).

Na quarta etapa do modelo, são definidos os processos de verificação e validação que vão garantir que o serviço projetado realmente atenda ao que foi identificado como necessidade. O modelo propõe a definição de uma sistemática para avaliação do serviço projetado e sua posterior validação pelo cliente, além de uma sistemática para recuperar clientes que não tenham suas necessidades e expectativas atendidas. Pode-se ainda, nesta etapa, revisar as etapas anteriores para um melhoramento no processo do projeto e desenvolvimento dos serviços.

\section{Pesquisa empírica}

A unidade de análise para a presente pesquisa é uma empresa de transporte rodoviário de passageiros, instalada no Estado de São Paulo, com 57 anos no mercado e 877 colaboradores. Seus ônibus percorrem várias cidades entre os Estados de São Paulo, Rio de Janeiro, Mato Grosso do Sul, Goiás e Tocantins.
Essa empresa foi escolhida por possuir um sistema de gestão da qualidade certificado pela norma NBR ISO 9001 (versão 2000), o que reforça sua preocupação com a qualidade e melhoria dos seus serviços e com a satisfação de seus clientes e de seus colaboradores. Além disso, ela facilitou o acesso do pesquisador aos dados necessários para a execução da pesquisa por necessitar desenvolver um novo serviço para minimizar suas perdas com evasão de renda na venda de passagens.

A escolha por uma empresa do setor de transporte se deu pela sua representatividade no cenário brasileiro. O setor de transporte é responsável por uma movimentação superior a 140 milhões de usuários/ano, sendo que o transporte de passageiros interestadual, em especial, é responsável por quase $95 \%$ do total dos deslocamentos realizados no País (AGÊNCIA NACIONAL DE TRANSPORTE TERRESTRE, 2005).

O novo serviço implantado na empresa, e que foi objeto desta pesquisa, foi a substituição das emissoras de cupom fiscal pela bilhetagem eletrônica como instrumento para 
melhoria do processo de arrecadação. O sistema convencional permitia a ocorrência de uma alta taxa de evasão, que a empresa visava combater com a implantação do novo sistema. As auditorias realizadas pelos inspetores da empresa detectaram que os cobradores burlavam o sistema de vendas de passagens, por exemplo, entregando ao cliente um ticket igual ao da emissora de cupom fiscal (ECF), porém em branco, alegando estar com problema na impressão do cupom; emitindo cupom com um trajeto menor solicitado pelo cliente, mas cobrando o trajeto maior; não preenchendo as passagens em aberto e revendendo-as numa outra oportunidade.

Para a implantação do modelo, utilizou-se um protocolo de pesquisa proposto por Mello (2005), disponível no Anexo B, visando aumentar a confiabilidade da pesquisa. $\mathrm{O}$ diagnóstico realizado pelo pesquisador com os integrantes do grupo de trabalho da empresa apontou a falta de um modelo sistemático que pautasse o processo de desenvolvimento de serviços. Esse primeiro seminário desencadeou todas as atividades descritas no item 2 deste trabalho para a seleção do modelo de referência a ser utilizado.

Uma vez escolhido o modelo de Mello (2005), descrito sucintamente no item 3 , o pesquisador iniciou a fase de coleta de dados para a verificação da adequação, e posterior implantação do referido modelo, por meio do método da pesquisa-ação. Para tal, o pesquisador utilizou de entrevistas semi-estruturadas (apoiadas por um roteiro incluso no protocolo de pesquisa do Anexo B), de observação direta e de consulta a documentos da empresa. Os dados coletados foram confrontados ao final de cada ciclo (ou etapa do processo de desenvolvimento), pela técnica da triangulação, visando analisar as convergências das várias fontes de evidências para aumentar a validade interna da pesquisa. Os tópicos a seguir apresentam as descrições da pesquisa realizada para implantação de cada uma das etapas do modelo de referência adotado.

\section{Etapa 1: projeto da concepção do serviço}

Para a implantação da fase de análise estratégica, foram realizadas, aproximadamente, cinco reuniões (seminários). Na primeira reunião, o pesquisador apresentou todas as etapas propostas pelo modelo à equipe envolvida no projeto.

Quando apresentado ao grupo envolvido no desenvolvimento do novo serviço, o gerente de mercado apontou que: "não temos como realizar uma análise estratégica da forma prevista pelo modelo. Somos uma empresa pioneira na implantação da bilhetagem eletrônica e não temos concorrência direta. Podemos apenas analisar aspectos ligados à relação custo-benefício". Tomando-se por base esta limitação, o pesquisador solicitou que fosse realizada uma pesquisa de mercado com o objetivo de levantar os possíveis sistemas existentes que atendessem às necessidades já verificadas. O pesquisador pôde perceber, nesta etapa, uma grande dificuldade para a implantação do modelo de referência de Mello (2005), uma vez que, pelo fato da empresa não possuir concorrentes diretos, não existia uma forma de comparar os serviços. Devido a essas dificuldades, as atividades para implantação da primeira etapa não foram realizadas conforme preconizado pelo modelo. Algumas adaptações foram necessárias e o pesquisador decidiu por dividir as atividades em partes para assim desenvolver uma análise estratégica.

Para segmentação e posicionamento no mercado, conforme o modelo previa, foi utilizada uma pesquisa realizada com o Instituto de Pesquisa Datafolha, que identifica o perfil do usuário, hábitos de viagem, flagrantes de viagem, avaliação dos serviços da empresa.

O pesquisador explicou e solicitou à equipe de trabalho que realizasse um plano de ação e um cronograma. Este cronograma continha desde a etapa de concepção até a de lançamento do serviço. O plano de ação informava as áreas de decisão estratégicas usadas na formulação da estratégia de operações do serviço, que serviram de base para as demais fases do modelo estudado.

As atividades de geração e seleção de idéias para o serviço proposto aconteceram por meio de decisões gerenciais. De acordo com as palavras dos gerentes de mercado e de auditoria:

é necessário buscarmos um maior controle na operação das linhas do serviço de transporte suburbano intermunicipal da empresa, especialmente no que diz respeito à quantidade de passageiros transportados e faturamento por linha, horário e seção. O objetivo é reduzir a evasão de receitas por fraude, especialmente nas linhas seccionadas (trajetos de até $75 \mathrm{~km}$ com seções entre origem e destino), e aumentar a segurança, pela diminuição do dinheiro em espécie no interior do ônibus.

Na reunião entre o pesquisador e a equipe da empresa estudada, cujo objetivo era selecionar idéias, o pesquisador definiu que a idéia selecionada deveria atender aos critérios já estabelecidos para a estratégia do serviço. Chegou-se rapidamente a um consenso de que a bilhetagem eletrônica poderia ser a solução para o problema de evasão de receitas.

Em relação à definição do pacote de serviços, estabeleceu-se que a bilhetagem eletrônica seria um serviço periférico incorporado ao serviço núcleo de transporte suburbano.

O grupo, juntamente com o pesquisador, resolveu que pelas necessidades internas levantadas, iria especificar os elementos principais do novo serviço. Para isso, o pesquisador fez um desdobramento do serviço e, juntamente com o grupo, definiu as especificações do novo serviço com base nos seguintes critérios: requisitos para monitoramento (sistemas inteligentes para monitora- 
mento, vendas, encerrante, coleta e movimento); preço; controle da catraca; controle de encerrante (fechamento do caixa diário de cada veículo); tipos de cartão (comum cadastrado, comum pré-carregado, estudante e valetransporte); tipos de equipamentos e suas especificações; características intrínsecas dos serviços.

\section{Etapa 2: projeto do processo do serviço}

$\mathrm{O}$ pesquisador apresentou à equipe de desenvolvimento as fases a serem completadas para a conclusão da segunda etapa do modelo e fez a seguinte consideração: "a organização precisa definir os principais processos que constituem o serviço e esses processos necessitam ser mapeados". Foram explicadas ao grupo as especificidades e diferenças de cada uma das técnicas de mapeamento de processos (service blueprint, mapa do serviço e IDEF) e, por consenso, o service blueprint foi a técnica selecionada, por identificar de forma simples tanto as atividades de linha de frente como as atividades de retaguarda, separadas pela denominada linha de visibilidade. Dessa forma, os principais processos foram mapeados.

Posteriormente, o pesquisador reuniu novamente o grupo para identificarem as atividades críticas que necessitavam ser descritas com maior precisão. Assim, foram elaborados os seguintes procedimentos: operacional do motorista; vendas de cartões nas agências; acerto de caixa entre agência e motorista; acerto de caixa entre agência e controladoria. Além disso, foram elaborados os roteiros (scripts) de cartão do estudante e de vale-transporte, para utilização pelos vendedores nos balcões das agências.

O modelo de referência estudado também previa que a organização deveria considerar a inclusão de mecanismos à prova de falhas nos padrões, para prevenir erros nos processos do serviço. Dessa forma, foram elaborados os seguintes documentos: necessidade da troca de carro devido a falhas, problemas com o sistema de bilhetagem eletrônica e outras anormalidades.

Para o recrutamento e seleção das pessoas para trabalharem com o novo serviço, o pesquisador, juntamente com o departamento de Recursos Humanos e a equipe técnica levantaram as indicações de qualificações mínimas do pessoal envolvido em todos os módulos do sistema de bilhetagem eletrônica, tais como escolaridade, habilidade e experiência. Os cargos essenciais para a implantação e entrega do serviço de bilhetagem eletrônica foram descritos, com suas principais funções e as devidas atribuições necessárias.

Por sugestão da gerente de auditoria e do pesquisador, foi criada uma equipe de apoio para apresentar o sistema aos usuários, pois havia uma preocupação com a mudança cultural a ser transposta pelos usuários em relação ao funcionamento do novo sistema.

Seguindo o protocolo de pesquisa, o pesquisador colocou em pauta qual seria o grau de autonomia que o funcionário de linha de frente iria dispor para atender ao usuário. Em consenso, a equipe de trabalho e o pesquisador concluíram que a padronização seria uma meta a ser cumprida e que o funcionário teria um baixo grau de autonomia neste serviço. O funcionário não poderia quebrar uma regra definida e seguiria sempre o padrão para satisfazer o cliente.

\section{Etapa 3: projeto das instalações do serviço}

Como a empresa analisada trabalha com concessão, tem-se uma limitação do trabalho para esta etapa da pesquisa. Os fatores locacionais considerados na definição da localização para a prestação do serviço foram as localidades que fazem parte das linhas em que a empresa opera. O objetivo principal é a interligação dos municípios do estado de São Paulo através de linhas e tarifas específicas. Sendo assim, o pesquisador fez uma adaptação e, junto com o gerente de mercado operacional, definiram as localizações que seriam atendidas.

Para a gestão das evidências físicas, o Gerente de Manutenção participou da reunião para definir o local no interior dos veículos que seriam instalados o validador embarcado, o conjunto de botoeiras do motorista (leitora de seccionamento) e a catraca eletromecânica (equipamentos necessários para o funcionamento da bilhetagem eletrônica).

O espaço físico (layout) do posto de atendimento é onde o serviço será prestado. Neste caso, houve a necessidade de adequação técnica dos veículos, tanto na funilaria quanto na parte elétrica para se adequar ao novo sistema de bilhetagem eletrônica. O consultor técnico da bilhetagem afirmou que:

a adequação técnica do salão do ônibus inclui a definição e alteração do posicionamento das catracas, quantidade e tipo de bancos antes da catraca e posicionamento dos balaústres.

A diretoria, a equipe de trabalho e o pesquisador não perceberam a necessidade de alterações na parte externa dos ônibus.

Para adequação das estruturas e instalações, foram necessárias obras civis em locais onde seriam instalados os módulos do sistema, tais como postos de vendas, postos de cadastro, postos de encerrante, o centro de processamento de dados e a área de coleta de dados. Essas obras nas instalações físicas propiciaram conforto físico aos operadores e usuários do sistema.

Para a análise da capacidade produtiva do serviço, uma das preocupações era a quantidade de cartões oferecida aos clientes, pois seria necessário evitar a ocorrência de espera causada por arranjos físicos incorretos. O pesquisador alertou para o problema da empresa não conseguir atender adequadamente a seus clientes nos períodos de pico. A equipe de trabalho realizou o estudo nas linhas 
de trajeto único (Araçatuba e Guararapes) e a de trajeto seccionado (Araçatuba e Penápolis) em relação aos horários, pontos de parada e à quantidade de pessoas que embarcam em cada ponto. Por meio da média de ocupação do veículo e da quantidade de viagens por linhas, determinou-se que o mais seguro seria entregar aos motoristas 60 cartões pagantes, mais 10 gratuitos por horário (viagem); além dos cartões comuns e melhor idade (para idosos acima de 65 anos), que ficariam à disposição nas agências para os clientes que preferissem utilizar estes tipos de cartões. Para as quantidades de cartões que seriam necessárias para atender a todo o processo de implantação do sistema de bilhetagem eletrônica, a equipe definiu, com base nos números de usuários estipulados pelo Departamento de Auditoria, que seria necessário confeccionar 20 mil cartões comuns. Os cartões estudantes e os de vale-transporte seriam confeccionados de acordo com a demanda dos clientes.

\section{Etapa 4: avaliação, melhoria e lançamento do serviço}

Para a atividade de verificação, o pesquisador sugeriu a criação de um check-list para cada departamento envolvido no processo de implantação do novo serviço: venda, suporte técnico, secretaria técnica e logística. Além do check-list, foram definidas as seguintes atividades para verificação da implantação do novo serviço: infra-estrutura física das agências e dos ônibus; leitura correta do GPS dos pontos de mudança de seção; definição dos pontos que seriam objeto de validação do serviço.

Para a definição da atividade de validação, o pesquisador sugeriu a realização de uma viagem piloto que, por intervenção da gerente de auditoria e do departamento de Logística, foi definida para se realizar em duas linhas: uma de trajeto único e outra de trajeto seccionado. $\mathrm{O}$ trajeto seccionado era também uma inovação para a empresa que estava dando suporte ao sistema de bilhetagem eletrônica que, em outros clientes, apenas havia implantado o sistema em empresas que operavam em trajeto único. A gerente de auditoria sugeriu "testar o serviço nas linhas mais próximas da sede, pela facilidade de controle e acompanhamento das atividades".

Para este propósito, as linhas escolhidas foram Araçatuba/Guararapes, por ser uma linha de trajeto único, e a linha Araçatuba/Lins, por ser uma linha do trajeto seccionado que atende também a outras cinco cidades do interior do estado de São Paulo. Para a linha de trajeto seccionado foi necessária a instalação da roleta e do validador na porta traseira do ônibus para garantir o controle do início e do fim da seção. No trajeto único, não foi necessário utilizar o validador e nem mesmo a roleta na porta traseira, mas como os ônibus servem para os dois tipos de linhas (único e seccionado), esses equipamentos são mantidos.
Para o teste piloto o pesquisador sugeriu que o grupo de apoio fizesse parte da viagem para identificar facilidades e dificuldades e desenvolveu uma planilha para registro de ocorrências. O grupo de apoio realizou o teste piloto, tanto nas agências como nos interiores dos ônibus em todos os horários de viagem, verificando os possíveis problemas: atrasos, quantidade de clientes que embarcavam e desembarcavam, quantidade de cartões disponíveis/necessários e tempo gasto em cada viagem. Os problemas identificados foram registrados na planilha de ocorrências.

O sistema escolhido para a bilhetagem eletrônica (TDSmart) oferecia relatórios nos quais, pela sua análise, podiam-se obter, com maior confiabilidade, a recuperação dos dados e a consequiente melhoria no serviço prestado.

Como a empresa possui certificação pela norma NBR ISO 9001 (versão 2000), a auditoria interna é um processo obrigatório. Sendo assim, o pesquisador participou da reunião do departamento de Auditoria, com a gerência operacional e com a consultoria da bilhetagem eletrônica para definir os relatórios que pudessem apoiar o processo de auditoria interna. $\mathrm{O}$ sistema de bilhetagem eletrônica possui relatórios de auditoria que visam identificar falhas operacionais e abusos de operadores e usuários, tais como: identificação de abusos de acesso, localização de tentativa de fraudes e identificação de viagens não realizadas.

Para a recuperação do serviço, o pesquisador apresentou as técnicas apontadas no modelo estudado, mas a equipe de trabalho selecionou as seguintes: 0800 como um canal aberto com o cliente; ressarcimento de clientes em situações que eles se sentissem ou fossem lesados; criação do cartão melhor idade para atender às necessidades dos clientes com idade superior a 65 anos; para todas as agências foi distribuído um cartaz de incentivo ao cliente para a troca da passagem em papel por um cartão; promoções de crédito.

Finalmente, a última atividade da etapa 4 é o lançamento do serviço. De forma a promover o lançamento desse novo serviço, o pesquisador sugeriu que a empresa realizasse uma promoção de créditos, como uma forma de incentivo aos clientes. O departamento Financeiro, a gerente de auditoria, o supervisor do departamento de mercado e o pesquisador desenvolveram uma promoção que foi aprovada pela diretoria da empresa.

\subsection{Análise estatística de verificação da implantação do serviço desenvolvido}

Para se avaliar se o serviço desenvolvido permitiu uma redução na evasão percentual de receitas da empresa estudada, procedeu-se a uma análise estatística de ANOVA. Na aplicação do teste de normalidade de Anderson-Darling sobre a "evasão de receitas", o valor de $p$-value foi menor que o nível de significância adotado $(\alpha<5 \%)$, o que conduziu à rejeição da hipótese nula de 
que os dados são bem ajustados pela distribuição normal. Como a variável não apresenta distribuição normal, foram empregadas duas estratégias de verificação: uma análise estatística não-paramétrica (Mediana de Mood) e a aplicação de uma ANOVA aos dados transformados (Transformação de Johnson).

$\mathrm{Na}$ aplicação da mediana de Mood, tanto para o trajeto único quanto para o seccionado, os valores de $p$-value nulos indicaram a rejeição da hipótese nula de igualdade entre as medianas da variável "evasão de receitas". Desse modo, pode-se afirmar que a evasão de receitas mediana observada no período pós-implantação do novo serviço de bilhetagem eletrônica é significativamente menor que com o serviço anterior.

Os dados foram submetidos à transformação de Johnson com posterior ANOVA na forma não-balanceada. Os valores de p-value inferiores ao nível de significância indicam, tanto para o trajeto único quanto para o seccionado, que a evasão média de receitas no período pós-implantação do serviço é significativamente menor do que o valor médio observado com o serviço de bilhetagem por emissão de cupom fiscal (ECF). Os gráficos da Figura 3 demonstram a diminuição da evasão de receitas com a implantação do novo serviço. Neste gráfico, o eixo y representa a média dos dados transformados, que guardam, apesar da mudança de escala, uma proporcionalidade e um sentido de correlação positiva entre as respostas original e transformada. O gráfico da Figura 3a apresenta esta análise para a quantidade de receitas evadidas no serviço de bilhetagem em trajeto único, enquanto que o gráfico da Figura $3 b$, apresenta as diferenças encontradas no caso de trajetos seccionados.

Para completar a análise estatística da melhoria proporcionada ao serviço estudado, propõe-se a análise da capacidade do processo para os dados transformados. Comparando os dados históricos com um limite superior de especificação para a evasão nos trajetos "único" e
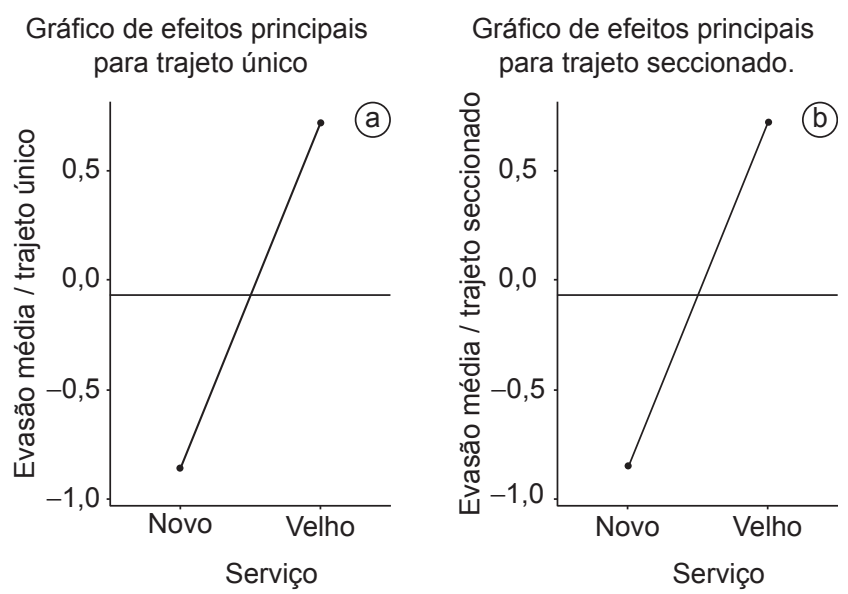

Figura 3. Gráfico fatorial de evasão por trajeto em função do serviço. "seccionado", obtém-se uma estimativa do novo desempenho do processo. Para o trajeto único, o valor de Ppk é 1,08 , o que equivale a um nível sigma de 4,74 . No caso do trajeto seccionado, o Ppk é igual a 1,10, o que equivale a um nível sigma de 4,87. Estes valores indicam um desempenho bastante razoável.

\section{Conclusões}

A presente pesquisa permitiu a implantação de um processo sistemático e documentado para o desenvolvimento de serviço na unidade de análise, tendo por base $\mathrm{o}$ modelo proposto por Mello (2005). Na formatação deste processo sistemático de desenvolvimento de serviços, diversos documentos foram gerados para padronizar as novas atividades a serem realizadas. O processo de verificação e validação do serviço desenvolvido passou a ser sistematizado e documentado. Dessa forma, considera-se que este estudo contribuiu para minimizar os três problemas identificados por Shostack (1984) para o processo de desenvolvimento de serviços.

O estudo e a aplicação do modelo de Mello (2005) na empresa analisada permitiram que algumas recomendações de melhoria fossem identificadas:

a) por se tratar de um modelo de referência genérico, proposto para ser utilizado para qualquer tipo de serviço (profissional, loja de serviços ou de massa), sugere-se que o modelo estudado seja adaptado para aplicação específica em cada tipo de serviço;

b) o processo de revisão de fases (stage-gates), tal como proposto por Cooper e Edgett (1999) e por Rozenfeld et al. (2006), também pode ser implementado no modelo estudado, de forma a assegurar um meio de estabelecer e avaliar critérios para decisão sobre a aprovação de cada etapa e o conseqüente início da etapa posterior; e

c) o modelo poderia considerar uma etapa suplementar de pós-desenvolvimento, tal como Rozenfeld et al. (2006) fazem para o modelo de referência para desenvolvimento de produtos.

As observações realizadas por meio da implantação do modelo revelaram alguns pontos fortes e também algumas limitações. Um dos pontos fortes foi o uso da análise estatística que contribuiu para justificar a escolha do modelo de Mello (2005). Outro ponto forte observado foi o maior controle das etapas de desenvolvimento do novo serviço de bilhetagem eletrônica e a possibilidade de uma melhoria contínua dos sistemas e dos processos envolvidos, oferecendo à organização uma ferramenta para o desenvolvimento de outros serviços com qualidade.

Como limitação da pesquisa, pode-se citar o fato dos respondentes empregados na seleção do modelo de referência adotado não serem especialistas no desenvol- 
vimento de serviços. Tentou-se minimizar essa limitação por meio de palestras aos respondentes acerca do processo e dos modelos de referência para o desenvolvimento de serviços.

De uma forma geral, pelos resultados obtidos, considera-se que a presente pesquisa contribuiu para o entendimento, ensino e aprendizagem da implantação do modelo de referência adotado para projeto e desenvolvimento de serviço na empresa estudada, que pode ser útil para o desenvolvimento de outros serviços. Além disso, a pesquisa verificou a adequação do modelo estudado no desenvolvimento do serviço de bilhetagem eletrônica na unidade de análise. Considera-se que ela atingiu os dois propósitos de uma pesquisa-ação: contribuir para o conhecimento científico (recomendações de aperfeiçoamento do modelo de referência adotado); e a resolução de um problema do objeto de estudo (ou contribuição prática), pela implantação de um processo sistemático para desenvolvimento de serviços na unidade de análise, proporcionando uma redução na evasão de receitas.

\title{
Analysis of a service project and a development model: an action-research in a road passengers transport company
}

\begin{abstract}
The aim of this work is to analyze the implementation of a reference model for the project and development of services in a road passenger Transport Company. The main goals were to minimize three problems related to services development process: the absence of systematic approach, the absence of documents and records that assure the control of the services development description, and the absence of tests documentation for the verification and validation of the developed service. The reference model was chosen by using multivariate analysis of variance and the actionresearch strategy. A smart card payment system service development for the road passengers' transport was the object of study. The research provided recommendations of improvements for the reference model and for the implementation of a systematic service development process in the company.
\end{abstract}

Keywords: Service development. Road passengers transportation. Reference models. Multivariate analysis of variance. Services.

\section{Referências bibliográficas}

AGENCIA NACIONAL DE TRANSPORTE TERRESTRE ANTT. Transporte de Passageiros. Disponível em: <http:// www.antt.gov.br>. Acesso em: 29 ago. 2005.

AMARAL, D. C. Arquitetura para gerenciamento de conhecimentosexplícitossobreoprocessodedesenvolvimento de produto. São Paulo, 2002. 215 p. Tese - (Doutorado em Engenharia Mecânica), Universidade de São Paulo - USP.

BARAT, J. A. Brief review of the development of urban transportation in Brazil. International Journal of Social Economics, v. 16, n. 12, p. 44-57, 1989.

BITRAN, G.; PEDROSA, L. A Structured Product Development Perspective for Service Operations. European Management Journal, v. 16, n. 2, p.169-189, 1998.

BOWERS, M. R. Developing New Services: improving the process maker in the better. The Journal of Services Marketing, v. 3, n. 1, p 15-20, winter, 1989.

BRYMAN, A. Research Methods and Organization Studies (Contemporary Social Research). 1 ed. London: Routledge, 1989.

COOPER, R. G.; EDGETT, S. J. Product development for the service sector. New York: Basic books, 1999.
COUGHLAN, P.; COGHLAN, D. Action research. Action research for operations management. International Journal of Operations \& Production Management, v. 22, n. 2, p. 220-240, 2002.

COWEL, D.W. New Service Development. Journal of Marketing Management, v. 3, n. 3, p. 296-312, 1988.

FITZSIMMONS, J. A.; FITZSIMMONS, M. J. New service development: creating memorable experiences. London: Sage Publications, Inc., 2000.

GEERLINGS, H.; KLEMENTSCHITZ, R.; MULLEY, C. Development of a methodology for benchmarking public transportation organizations: a practical tool based on an industry sound methodology. Journal of Cleaner Production, v. 14, n. 2, p. 113-123, 2006.

LIMA, E. P. Uma modelagem organizacional baseada em elementos de natureza comportamental. Florianópolis, 2001. 297p. Tese - (Doutorado em Engenharia de Produção), Universidade Federal de Santa Catarina - UFSC.

MELLO, C. H. P.; CHIMENDES, V. C. G.; TURRIONI, J. B. Setor de serviços: áreas a serem exploradas para o desenvolvimento de pesquisa. In: SIMPÓSIO DE ENGENHARIA DE PRODUÇÃO 
- UNESP, 12, Novembro de 2005, Bauru. Anais... Bauru: Unesp, 2005. Disponível em: < http://www.simpep.feb.unesp. br/anais.php>. Acesso em: 17 ago. 2006.

MELLO, C. H. P. Modelo para projeto e desenvolvimento de serviços. São Paulo, 2005. 317p. Tese - (Doutorado em Engenharia da Produção), Escola Politécnica da Universidade de São Paulo - USP.

MELO, H. P. et al. O setor de serviços no Brasil: uma visão global - 1985/95. Rio de Janeiro: IPEA, 1998. (texto para discussão número 549). Disponível em: <http://www.ipea.gov.br/default. jsp>. Acesso em: 12 abr. 2006.

MONTGOMERY, D. C.; RUNGER, G. C. Estatística aplicada e probabilidade para engenheiros. 2 ed. Rio de Janeiro: LTC, 2003.

PONTES. A. C. F. Análise de variância multivariada com utilização de testes não paramétricos e componentes principais baseados em matrizes de postos. Piracicaba, 2005. 106p. Tese -(Doutorado em Agronomia), Escola Superior de
Agricultura "Luiz de Queiroz", Universidade de São Paulo USP.

RAMASWAMY, R. Design and management of service processes. Keeping custumers for life. Engineering Process Improvemet Series. Massachusetts: Addison-Wesley Publishing Company, 1996.

RENCHER, A. C. Methods of Multivariate Analysis. 2 ed. New York: John Wiley \& Sons, 2002.

ROZENFELD, H. et al. Gestão de desenvolvimento de produtos. São Paulo: Editora Saraiva, 2006.

SCHEUING, E. E.; JOHNSON, E. M. A proposed model for new service development. The Journal of Services Marketing, v. 3, n. 2, Spring, 1989, p. 25-32.

SHOSTACK, G. L. Designing services that deliver. Havard Business Review, p.133-139, January-February, 1984.

TAX, S. S.; STUART, I. Designing and implementing new services: the challenges of integrating service systems. Journal of Retailing, v. 73, n. 1, p. 105-134, 1997.

\section{Anexos}

Anexo A. Questionário de pesquisa para seleção de modelo para projeto e desenvolvimento de serviços.

\begin{tabular}{|c|c|c|c|c|c|c|c|c|}
\hline \multirow[t]{2}{*}{ Critérios } & \multirow{2}{*}{$\begin{array}{c}\text { Notas } \\
1 \text { - Discordo totalmente; } 2 \text { - Discordo com restrições; } \\
3 \text { - Concordo com restrições; } 4 \text { - Concordo totalmente }\end{array}$} & \multicolumn{7}{|c|}{ Modelos } \\
\hline & & A & B & $\mathbf{C}$ & D & $\mathbf{E}$ & $\mathbf{F}$ & G \\
\hline \multicolumn{9}{|c|}{ 1. O modelo contempla uma etapa de análise estratégica do mercado. } \\
\hline \multicolumn{9}{|c|}{ 2. O modelo contempla uma etapa de geração e seleção de idéias para um novo serviço. } \\
\hline \multicolumn{9}{|c|}{ 3. O modelo contempla uma etapa para definição das especificações do novo serviço. } \\
\hline \multicolumn{9}{|c|}{ 4. O modelo contempla uma etapa para definição do conceito e do pacote do serviço. } \\
\hline \multicolumn{9}{|c|}{ 5. O modelo contempla uma etapa para teste do conceito definido para o novo serviço. } \\
\hline \multicolumn{9}{|c|}{ 6. O modelo contempla uma etapa de autorização pela direção da empresa para início formal do projeto. } \\
\hline \multicolumn{9}{|c|}{ 7. O modelo contempla uma etapa de projeto dos processos de realização do novo serviço. } \\
\hline \multicolumn{9}{|c|}{ 8. O modelo contempla uma etapa de projeto das instalações e evidências físicas para o novo serviço. } \\
\hline \multicolumn{9}{|c|}{ 9. O modelo contempla uma etapa para avaliação da capacidade produtiva do novo serviço. } \\
\hline \multicolumn{9}{|c|}{ 10. O modelo contempla uma etapa para teste do novo serviço antes da sua entrega ao cliente. } \\
\hline \multicolumn{9}{|c|}{ 11. O modelo contempla uma etapa para definição de um programa de marketing para o novo serviço. } \\
\hline \multicolumn{9}{|c|}{ 12. O modelo contempla uma etapa de análise das melhorias do projeto e para recuperação de falhas. } \\
\hline \multicolumn{9}{|c|}{ 13. O modelo contempla uma etapa para definição da estratégia de lançamento do serviço no mercado. } \\
\hline \multicolumn{2}{|c|}{$\begin{array}{l}\text { 14. O modelo contempla uma etapa para revisão de pós-lançamento do serviço e realimentação para } \\
\text { registro de lições aprendidas durante o desenvolvimento do serviço. }\end{array}$} & & & & & & & \\
\hline \multicolumn{8}{|c|}{ 15. Cada uma das etapas do modelo é de fácil entendimento. } & \\
\hline \multicolumn{9}{|c|}{ 16. As etapas do modelo são seqüenciais, apresentando coerência da primeira etapa até a última. } \\
\hline \multicolumn{9}{|c|}{ 17. O modelo representa uma visão holística (completa) do processo de desenvolvimento de serviço. } \\
\hline \multirow{2}{*}{\multicolumn{2}{|c|}{$\begin{array}{l}\text { 18. O modelo pode ser aplicado em uma empresa de transporte rodoviário de passageiros. } \\
\text { 19. O modelo se adapta para ser implementado no processo de desenvolvimento de serviços da empresa. }\end{array}$}} & & & & & & & \\
\hline & & & & & & & & \\
\hline
\end{tabular}


Anexo B. Protocolo de pesquisa.

Protocolo de pesquisa

\section{Modelo para projeto e desenvolvimento de serviço}

Pesquisa de campo - Dissertação de Mestrado

\section{Método de pesquisa: Pesquisa-ação.}

\section{Técnicas de coleta de dados}

1. Entrevistas semi-estruturadas, realizadas durante as visitas à unidade de análise. Total de visitas: 15 a 20, com duração de 120 minutos cada visita. Dividir as visitas conforme o andamento do processo de desenvolvimento do novo serviço (objeto de pesquisa). Verificar as questões (abaixo) a serem respondidas, conforme a respectiva etapa de desenvolvimento do serviço.

2. Observação direta da realização das atividades, para confrontar com as informações obtidas durante as entrevistas. Analisar práticas e comportamentos dos entrevistados.

3. Análise de documentos: solicitar e analisar os documentos da empresa sobre as práticas atuais de desenvolvimento de serviços, para comparação das evidências coletadas.

Forma de registro: Solicitar permissão para o uso de gravador. Registrar os dados mais importantes ou frutos da observação direta e da análise de documentos em formulários próprios.

Informantes/respondentes: Pessoas ligadas ao processo de desenvolvimento de serviços da unidade de análise (equipe multidisciplinar), composta por: Supervisor de Agência, Gerente de Suprimentos, Gerente de Mercado, Gerente Técnico, Gerente de Vendas, Gerente de Auditoria, Diretor Operacional, Gerente Financeiro, Gerente de Manutenção, Encarregado da Manutenção, Gerente de Recursos Humanos.

\begin{tabular}{ll}
\hline Etapa/ & Questões \\
item &
\end{tabular}

Etapa 1. Projeto da concepção do serviço:

1. A organização realizou uma análise estratégica para a concepção de seus novos serviços? As estratégias de segmentação, posicionamento e foco do novo serviço foram consideradas?

2. Que critérios competitivos foram priorizados pela organização durante a análise estratégica para atender às necessidades e expectativas dos clientes? Quais vantagens competitivas foram alcançadas? A satisfação dos clientes aumentou?

3. A organização definiu o conceito para seus novos serviços?

4. A organização avaliou as diferenças (ou gaps) percebidas entre o que o mercado necessita, o que ele (provedor do serviço) pode oferecer e o que os seus concorrentes estão oferecendo para o segmento de mercado focado? Que ferramentas foram usadas?

5. A organização elaborou um cronograma de projeto para pautar as etapas e fases a serem realizadas para o projeto e desenvolvimento de seus novos serviços?

6. Como e de onde partiu a idéia para o projeto e desenvolvimento dos novos serviços? Que ferramentas ou técnicas a organização utilizou para a geração de idéias para a concepção de seus novos serviços? E para a seleção das idéias geradas?

7. A organização definiu o pacote que o novo serviço irá oferecer aos seus clientes? A definição do pacote considerou o serviço principal e os secundários?

8. A organização definiu especificações para o processo de serviço com base na análise estratégica realizada? As especificações compreendem aspectos tangíveis e intangíveis do serviço a ser projetado e desenvolvido?

9. Que fontes foram usadas pela organização para o estabelecimento das especificações do serviço? Quais as ferramentas usadas para a tradução das necessidades dos clientes em especificações do serviço?

Etapa 2. Projeto do processo do serviço

1. A organização definiu os principais processos que constituem o serviço? Esses processos foram mapeados? Que técnica a organização empregou no mapeamento dos processos do serviço?

2. Após mapear os processos, a organização padronizou de forma documentada as atividades do processo? A padronização incluiu as atividades de linha de frente e de retaguarda?

3. A adoção do mapeamento dos processos permitiu a melhoria do entendimento sobre o processo por parte dos colaboradores?

4. A organização considerou a inclusão de sistemas à prova de falhas nos padrões para prevenir falhas nos processos do serviço?

5. Que fatores a organização considerou ao projetar e desenvolver o processo ou o ambiente de entrega do serviço (encontro do serviço)?

6. A organização considerou os canais de comunicação não-verbais ao projetar o ambiente de encontro do serviço?

7. O projeto do processo do serviço considerou o desenho do perfil profissional dos funcionários a serem contratados? Que características do perfil dos funcionários são consideradas para a sua contratação? O perfil é diferente para funcionários de linha de frente e de retaguarda?

8. $\quad$ A organização definiu as necessidades de treinamento dos funcionários que desempenharão o novo serviço? O mesmo para habilidades e experiência?

9. Qual o grau de autonomia que o funcionário de linha de frente dispõe para atender ao seu cliente? Ele pode quebrar uma regra definida em um padrão para satisfazer um cliente? 


\section{Protocolo de pesquisa}

\section{Modelo para projeto e desenvolvimento de serviço}

Pesquisa de campo - Dissertação de Mestrado

Etapa 3. Projeto das instalações do serviço

1. Quais os fatores locacionais foram considerados na definição da localização para a prestação do serviço?

2. Quais ferramentas ou técnicas a organização utilizou para a seleção do local para a prestação do serviço?

3. Como a organização definiu o layout do ambiente de encontro do serviço?

4. Como a organização definiu e selecionou os equipamentos necessários à prestação do serviço?

5. Que outros aspectos (cores, limpeza, iluminação, etc.) a organização considerou no projeto de suas instalações? Qual o impacto desses aspectos na percepção do cliente?

6. A organização estudou a capacidade produtiva do serviço que está sendo projetado?

7. Por qual estratégia de capacidade produtiva a organização optou? Por quê?

8. Como a organização estimou a capacidade produtiva pretendida pelo serviço? Que técnicas ou ferramentas foram empregadas?

Etapa 4. Avaliação e melhoria do serviço:

1. A organização implementou atividades de verificação do projeto e desenvolvimento do serviço?

2. Que características foram consideradas na verificação? Os resultados da verificação foram registrados?

3. A organização implementou atividades de validação do projeto e desenvolvimento do serviço?

4. A organização envolveu a construção de um protótipo ou de uma operação-piloto? Os resultados da validação foram registrados?

5. A realização da verificação e da validação do serviço contribuiu para uma redução na incidência de falhas no serviço ou na reclamação de clientes?

6. A organização estabeleceu uma estratégia para a recuperação do serviço durante a fase de projeto e desenvolvimento?

7. A organização estabeleceu alguma forma de estimular a melhoria contínua do seu processo de projeto e desenvolvimento?

8. São realizadas pesquisas com clientes freqüentemente?

9. As pesquisas de satisfação de clientes mostraram aumento na satisfação dos clientes que tiveram seus serviços recuperados?

10. As auditorias internas do sistema de gestão da qualidade mostraram uma redução do número de não-conformidades detectadas nos serviços desenvolvidos segundo a metodologia de projeto?

\section{Sobre os autores}

\section{Vanessa Cristhina Gatto Chimendes}

\section{Carlos Henrique Pereira Mello}

\section{Anderson Paulo de Paiva}

Instituto de Engenharia de Produção e Gestão - IEPG, Universidade Federal de Itajubá - UNIFEI, Av. BPS, 1303, Bairro Pinheirinho, CEP 37500-903, Itajubá, MG, Brasil,

e-mails: vcgatto@uol.com.br; carlos.mello@unifei.edu.br; andersonppaiva@yahoo.com.br

Agradecimentos: os autores agradecem aos referees pelos úteis comentários e sugestões de melhoria para este trabalho e à empresa participante desta pesquisa pelas informações fornecidas. 